\title{
The Egg and Larva of Callionymus lyra.
}

\author{
By
}

\section{J. T. Cunningham, M.A.}

With Plate V.

THE egg of this species has been described and discussed by Professors McIntosh and Prince, by Mr. E. W. L. Holt, and by myself.* Raffaele, in his paper in the Mittheilungen of the Naples Station, vol. viii, described the yolk in the ovum of Callionymus festivus as having a peripheral layer of yolk-segments, but no reticulated marking on the surface of the vitelline membrane; while all we English observers have agreed in stating that the egg of Callionymus lyra, our common dragonet, has a reticulated marking on the vitelline membrane, but no yolk-segments. I was, therefore, very much surprised, in examining some eggs of this species from the tow-net this year, to find that there actually was a peripheral layer of yolk-segments, which had hitherto been overlooked.

Raffaele states that in Callionymus festivus, the Mediterranean species, the yolk-segments extend all round the yolk from the beginning, before it has been enveloped by the blastoderm. Whether this is correct in 0 . festivus or not, it does not apply to C. lyra. In the ovum shown in $\mathrm{Pl}$. $\mathrm{V}$, fig. 1 , which was taken in the tow-net on May 14th, 1891, the blastoderm has spread over about one third of the circumference of the yolk, and the layer of yolk-segments extends beneath the blastoderm and somewhat beyond it, but is absent from the opposite pole of the yolk. An egg of the same species at a later stage, in which the yolk is completely enveloped, and Kupffer's vesicle has appeared beneath the posterior end of the embryo, is shown in fig. 2, and it will be seen that at this stage the external subdivided layer extends over the whole of the yolk. Thus the layer of yolk-segments in the egg of $C$. lyra is at first confined to

* See Ann. and Mag. Nat. Hist., Dec., 1885 ; Memoir by McIntosh and Prince in Trans. Roy. Soc. Edinb., vol. xxxv, pt. 3, 1890; my paper in this Journal, vol. i, p. 21; Mr. Holt's Memoir in Sci. Trans, Roy. Dublin Soc., vol. iv, ser. 2, No. 7. 
the part of the yolk beneath the blastoderm, and accompanies the latter in its gradual extension, just as in the eggs of Solea and in other cases where the peripheral yolk-segments occur.

There can, I think, be no doubt about the identification of the eggs I refer to. I have never found in the egg of any other species anything resembling the hexagonal reticulation in the membrane of the egg of the dragonet. The size of the eggs described here was . 81 and $.83 \mathrm{~mm}$. in diameter, while those described in my former paper measured 90 and $\cdot 97$, a variation not greater than that which occurs among the eggs of a given species.

Mr. Holt (loc. cit.) has given figures of the larval dragonet when just hatched, and about twelve hours after hatching. I am able now to give a figure of a later stage. The larva depicted in fig. 3 was drawn on May 14th, and hatched from an egg taken on May 6th, so that it was probably five or six days old. The yolk is entirely absorbed, but the larva retains some of the characteristics mentioned by Holt. There are marginal pigment spots on the embryonic finfold, but they are more numerous than in the stage figured by Holt; while there is no band across the tail, but pigment over nearly the whole of the post-anal portion of the body. The pectoral fin is large. The snout has still a somewhat pointed form, but the region of the mid-brain is much more prominent than in Holt's stage. Holt speaks of only one pigment, a bright orange, dark by transmitted light, and I gather from his description that in the stages he examined he saw no black chromatophores. I think this must be a mistake ; in any case there are, as usual, both black and coloured chromatophores in the stage I am describing, the coloured cells being light yellow by reflected light and darker yellow by transmitted. The length of the larva was $4.7 \mathrm{~mm}$.

\section{DESCRIPTION OF PLATE $\nabla$,}

Illustrating Mr. Cunningham's paper on "The Egg and Larva of Callionymus lyra."

Fig. 1.-Egg of Callionymus lyra, taken May 14th, 1891. Zeiss A, Oc. 3. Under coverglass, drawn with Abbé's camera lucida.

bl. Blastoderm.

y. s. Yolk-segments.

Fig. 2.-Another egg at a later stage of development. Drawn with the same combination, without cover-glass.

$k$. v. Kupffer's vesicle.

y.s. Yolk-segments.

FIG. 3.-Larva of same species some days after hatching. Drawn May 14th, 1891.

iss $\mathrm{a}_{3}$, Oc. 3 , camera. 


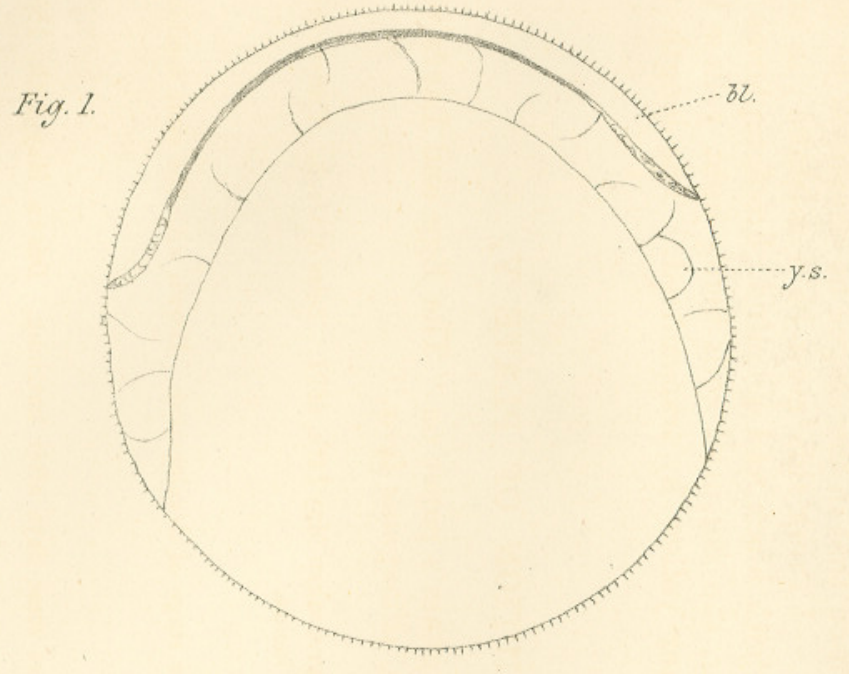

Fig. 3.
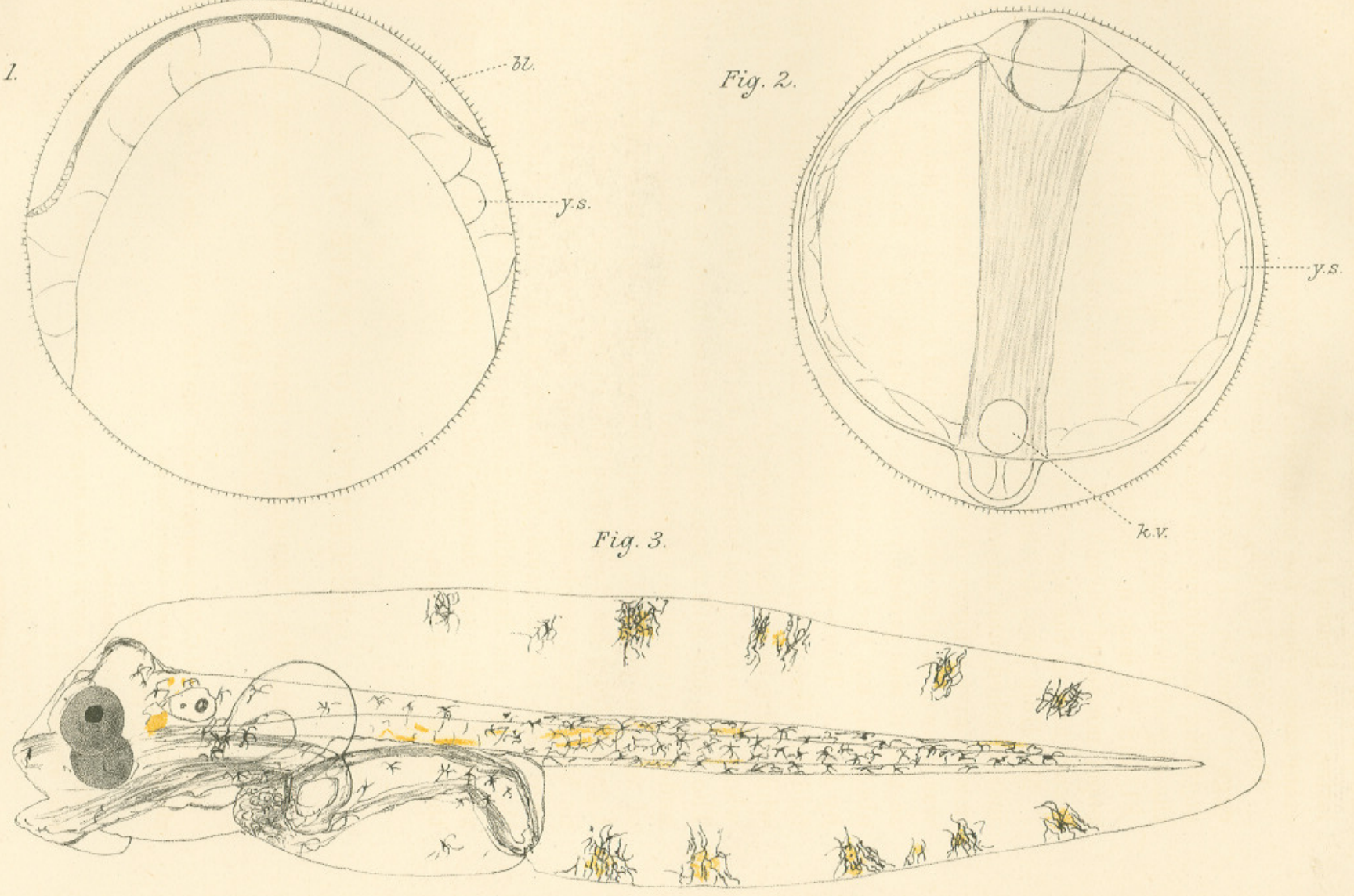